\title{
The Effect of High-dose Parenteral Sodium Selenite in Critically III Patients following Sepsis: A Clinical and Mechanistic Study
}

\author{
Legese Chelkeba ${ }^{1,2,3,4}$, Arezoo Ahmadi², Mohammad Abdollahi³ ${ }^{3}$, Atabak Najafi' ${ }^{2}$, Mohammad Hosein Ghadimi³, Reza Mosaed ${ }^{3}$, Mojtaba Mojtahedzadeh ${ }^{1,2,3}$ \\ DDepartment of Clinical Pharmacy, Faculty of Pharmacy, Tehran University of Medical Sciences, International Campus, ${ }^{2}$ Department of Anesthesiology and Critical \\ Care Medicine, Sina Hospital, Faculty of Medicine, Tehran University of Medical Sciences, ${ }^{3}$ Faculty of Pharmacy and Pharmaceutical Sciences Research Center, Tehran \\ University of Medical Sciences, Tehran, Iran, ${ }^{4}$ Department of Clinical Pharmacy, Faculty of Health Sciences, Jimma University, Jimma, Ethiopia
}

\section{Abstract}

Introduction: Severe sepsis and septic shock is characterized by inflammation and oxidative stress. Selenium levels have been reported to be low due to loss or increased requirements during severe sepsis and septic shock. We investigated the effect of high-dose parenteral selenium administration in septic patients. Methods: A prospective, randomized control clinical trial was performed in septic patients. After randomization, patients in selenium group received high-dose parenteral sodium selenite ( $2 \mathrm{mg}$ intravenous [IV] bolus followed by $1.5 \mathrm{mg}$ IV continuous infusion daily for 14 days) plus standard therapy and the control group received standard therapy. The primary endpoint was mortality at 28 days. Changes in the mean levels of high mobility group box-1 (HMGB-1) protein and superoxide dismutase (SOD), duration of vasopressor therapy, incidence of acute renal failure, and 60 days' mortality were secondary endpoints. Results: Fifty-four patients were randomized into selenium group $(n=29)$ and control group $(n=25)$. There was no significant difference in 28 -day mortality. No significant difference between the two groups with respect to the average levels of HMGB-1 protein and SOD at any point in time over the course of 14 days had observed. Conclusion: In early administration within the first $6 \mathrm{~h}$ of sepsis diagnosis, our study demonstrated that high-dose parenteral selenium administration had no significant effect either on 28-day mortality or the mean levels of HMGB-1 and SOD (Trial Registration: IRCT201212082887N4 at WHO Clinical Trial Registry, August 29, 2014).

Keywords: High mobility group box-1 protein, mortality, selenium, sepsis, septic shock, severe sepsis, superoxide dismutase

\section{INTRODUCTION}

The incidence of sepsis was high and in the United States it is estimated to be $300 / 100,000$ population per year. ${ }^{[1]}$ The spectrum of disease is a major cause of morbidity and mortality globally, with mortality in severe sepsis $\geq 5$-fold higher than that for acute coronary syndrome or stroke. ${ }^{[2]}$ With advances in health-care services and technology, appropriate organ support, and treatment of the underlying inciting pathogens, the mortality rate is still $20 \%-50 \%{ }^{[3]}$

During infection, pathogens or cellular components are recognized by receptors expressed on the surface of the innate immune cells known as pattern recognition receptors. The same receptors often recognize damage-associated molecular patterns (DAMPs) indicating that the similarities between pathogen-induced and inflammatory responses to cellular stress, injury, or necrosis. ${ }^{[4]}$ Trauma or injury generates danger-associated molecular patterns (i.e., high mobility

\begin{tabular}{|l|l|}
\hline \multicolumn{3}{c|}{ Access this article online } \\
\hline Quick Response Code: & Website: \\
& www.ijccm.org \\
\hline
\end{tabular}

group box-1 [HMGB-1], heat shock proteins, and S100 proteins) that augment toll-like receptors expressions such as pathogen-associated molecular patterns. ${ }^{[5]}$ HMGB-1, one of the most extensively studied DAMPs, is a protein involving in nuclear stabilization and gene transcription which, if released in large quantities into the extracellular environment, becomes a lethal mediator of systemic inflammation. ${ }^{[6,7]}$ A significant amount of HMGB-1 levels have observed in majority of patients up to a week after the diagnosis of sepsis or septic shock and are correlated with the degree of organ dysfunction. ${ }^{[6]}$

Address for correspondence: Dr. Legese Chelkeba, Department of Clinical Pharmacy, Faculty of Health Sciences, Jimma University, Jimma, Ethiopia. E-mail: legese.chelkeba@gmail.com

This is an open access article distributed under the terms of the Creative Commons Attribution-NonCommercial-ShareAlike 3.0 License, which allows others to remix, tweak, and build upon the work non-commercially, as long as the author is credited and the new creations are licensed under the identical terms.

For reprints contact: reprints@medknow.com

How to cite this article: Chelkeba L, Ahmadi A, Abdollahi M, Najafi A, Ghadimi MH, Mosaed R, et al. The effect of high-dose parenteral sodium selenite in critically ill patients following sepsis: A clinical and mechanistic study. Indian J Crit Care Med 2017;21:287-93. 
The surviving sepsis campaign (SSC $)^{[8]}$ guidelines recommended early goal-directed therapy (EGDT) as a strategy to reduce mortality in severe sepsis and septic shock patients since the work of Rivers and colleagues. ${ }^{[9]}$ However, new studies revealed that EGDT versus standard therapy has not changed mortality. ${ }^{[10-12]}$ That tells us other than fluid and antibiotics, other treatment alternatives may have survival benefits. These potential interventions could be immunomodulator therapies since sepsis is characterized by early hyperinflammatory state and late immunosuppression. ${ }^{[13]}$ Because the immune mechanisms play a key role in vascular dysfunction, it seems that improvement in immune function concedes with hemodynamic improvement and hence immunomodulators help the standard therapy to be effective. ${ }^{[14]}$ Selenium is an essential trace element for the biosynthesis and function of about 25 known selenocysteine-containing selenoproteins, located on the catalytic center of most selenoenzymes. ${ }^{[15]}$ One of the best known and characterized redox systems is glutathione complex consisting of the selenium-dependent peroxidases and the thioredoxin reductases. ${ }^{[16,17]}$

A study showed that the level of selenium in critically ill patients decreased due to loss into interstitial compartment, hemodilution, previous insufficient intake, and continuous renal replacement therapy that is incompletely replaced. ${ }^{[18]}$ In addition, selenium requirements may increase during inflammatory conditions because of the increase in oxidative stress and production of reactive oxygen species. ${ }^{[19]}$ As a result, low levels of selenium have been associated with oxidative stress, infectious complications, worsening organ failure, and higher mortality rate, ${ }^{[18]}$ although meta-analyse ${ }^{[20-22]}$ and controlled clinical trials in diverse groups of critical illness have failed to demonstrate consistent benefit in terms of clinical outcomes. ${ }^{[23-29]}$ To date, we have two groups of information on the effect of selenium in critically ill patients: studies with promising results of improvement in clinical outcomes ${ }^{[30,31]}$ and trails with no effect. ${ }^{[26,28,32,33]}$ A number of meta-analysis also reported conflicting results about the survival benefits of selenium in critically ill patients. ${ }^{[34-37]}$ Hence, currently we do not have clear evidence whether parenteral selenium supplementation should be routinely administered to critically ill patients with sepsis or not. The aim of the current study was, therefore, to evaluate the possible impact of high-dose intravenous (IV) selenium supplementation on 28-day mortality, 60-day mortality, the average plasma levels of HMGB-1 protein and superoxide dismutase (SOD), duration of vasopressor therapy, and incidence of renal failure in critically ill patients following sepsis.

\section{Methods}

\section{Study design and patient selection}

This was a prospective, single-centered, single-blinded, randomized control clinical trial (RCT) conducted on septic patients admitted to the Intensive Care Unit (ICU) to determine the effect of selenium in septic patients. Patients were recruited from 2012 to December 2014 whereby 54 patients with sepsis, severe sepsis, or septic shock were eligible for inclusion and were prospectively enrolled. The study was conducted in accordance with the Declaration of Helsinki and was approved by the Ethics Committee (code of ethical approval: 1-1: 90-3-29). Oral and written informed consent was obtained from the patients or their close relatives. Moreover, an identification code assigned to each patient was used instead patient's name to protect the patient's identity when reporting trial-related data.

\section{Inclusion and exclusion criteria}

- Patients were included if at least with two of the following four criteria plus infection:

1. Body temperature $>38^{\circ} \mathrm{C}$ or hypothermia $<36^{\circ} \mathrm{C}$

2. Heart rate $>90$ beats $/ \mathrm{min}$, respiratory frequency $>20$, and arterial pressure of carbon dioxide $\left(\mathrm{PaCO}_{2}\right)$ $<32 \mathrm{mmHg}$

3. Leukocytes $>12,000 / \mu \mathrm{L}$ or $<4000 / \mu \mathrm{L}$ or

4. $>10 \%$ immature leukocytes

- $\quad$ Age $\geq 17$ years

- Enrollment into the study after diagnosis within $6 \mathrm{~h}$

- Informed consent either from the patient or the relative obtained.

The exclusion criteria were

- Age $<17$ years

- Pregnancy

- Missing informed consent either from the patient or the relative

- Prior participation in this clinical trial

- Chronic kidney disease

- Discharged before $48 \mathrm{~h}$ of ICU admission

- Cancer as the cause of systemic inflammatory response syndrome or sepsis and if medical staff decided to limit care.

\section{Randomization and protocol}

Consecutive eligible patients were recruited and randomized via block randomization into four blocks in which a random selection was done using a list of numbers generated using statistical software. Half of the patients in each block were allocated to selenium and the remaining half to control group. Boxes containing the whole treatment for each patient were delivered to the investigator by the hospital pharmacist following the order of the randomization list. All patients remained blinded throughout the study period. Standard treatments for severe sepsis and septic shock were given according to the SSC. ${ }^{[8]}$ Patients in selenium group received $2000 \mu \mathrm{g}$ of sodium selenite in $100 \mathrm{~mL}$ of normal saline within the first $6 \mathrm{~h}$ of diagnosis of sepsis during $1 \mathrm{~h}$ intravenously followed by $1500 \mu \mathrm{g}$ of sodium selenite in $250 \mathrm{~mL}$ of normal saline during $12 \mathrm{~h}$ continuously for 14 days. The control groups received standard therapy without selenium. Patients otherwise were treated according to the best practice of the hospital, including parenteral or enteral nutrition together with vitamins and trace elements as necessary. The intervention drug was 
supplied by Biosyn Arzneimittel GmBH (Fellbach, Germany). All hemodynamic data were monitored during the infusion, and in case of any negative hemodynamic deterioration or any reaction, the infusion was discontinued. We defined sepsis according to criteria proposed by the American College of Chest Physicians/Society of Critical Care Medicine. ${ }^{[38]}$

\section{Data collection}

Individual clinical data were registered for the patients on structured questionnaire. Sociodemographic data (age and gender), time between admission to the ICU and enrollment into the study, Sequential Organ Failure Assessment (SOFA), and Acute Physiologic and Chronic Health Evaluation II (APACHE II) score on the day of admission, admission diagnosis, comorbidities, site of infection, severity of sepsis, and type of pathogens were also recorded.

\section{Follow-up}

Patients were followed up for 90 days or till they died, depending on which happened first. The average plasma levels of HMGB-1 protein and SOD analyzed on days $0,3,7,10$, and 14 were recorded. 28 - and 60-day mortality was also registered. Any adverse outcome from infusion of selenium was noticed.

\section{Study endpoints}

The primary endpoint was 28-day mortality. The average changes in the plasma levels of HMGB-1 and SOD over the course of 14 days, 60 days mortality, and incidence of renal failure and duration of vasopressor therapy were the secondary endpoints. Acute renal failure was defined by increased levels of creatinine at least twice normal and/or urine output of $<0.5 \mathrm{~mL} / \mathrm{kg} / \mathrm{h}$ for $\geq 12 \mathrm{~h}$.

\section{Sample collection, handling, and laboratory analysis}

Blood samples ( $5 \mathrm{~mL}$ each) were taken from central venous catheters and arterial lines that all patients had. The first samples were obtained upon diagnosis of sepsis, but before initiation of the therapy (designated as day 0 ). Other samples were obtained on days $3,7,10$, and 14 of sepsis diagnosis. The blood samples were collected into vacutainer tubes containing EDTA and spun these samples at $3000 \times g$ for $10-15 \mathrm{~min}$ to remove cells and cellular debris. The cell-free supernatant and plasma were stored at $-80^{\circ} \mathrm{C}$ until the time of the analyses. The levels of HMGB-1 and SOD were analyzed through automated enzyme-linked immunosorbent assay kit (Human $\mathrm{Cu} / \mathrm{ZnOD}$, Affymetrix eBioscience, Vienna, Austria) according to the manufacturer's instructions. The other routine laboratory analyses including microbiological findings were done as per the attending physician prescription in the hospital laboratory from day 1 of inclusion till the patient discharged or died. Blood cultures and cultures of specimens drawn from the site of infection were routinely obtained.

\section{Sample size calculation}

The sample size was calculated on the base of $5 \%$ significance level and $80 \%$ power to detect a $20 \%$ reduction in 28 -day mortality in the study population based on the result of previous study. ${ }^{[33]}$ The calculated sample size based on this information was 92 patients; 46 patients in each arms. However, the recruitment process was slow and we included only 54 patients in the final analyses.

\section{Statistical analysis}

Discrete variables are expressed as counts (percentage) and continuous variables as means \pm standard deviation and categorical data were compared using the Chi-square test, Fisher's exact test, or the Cochran-Mantel-Haenszel test as appropriate for categorical variables. The Kolmogorov-Smirnov test was used to verify the normality of distributions of continuous variables. Continuous variables conforming to a normal distribution were compared using Student's $t$-test otherwise the Mann-Whitney U test was applied. Changes in HMGB-1 protein and SOD levels over time as a function of group were analyzed by performing the repeated measures of variance. $P<0.05$ was considered statistically significant. The data were analyzed using SPSS 22.0 for Windows software (SPSS, Chicago, IL, USA).

\section{REsULTS}

\section{Patients' selection and recruitment}

We assessed 364 patients for eligibility, of which 310 patients were excluded for the following reasons: 257 patients were excluded for not fulfilling the inclusion criteria, 2 patients decline not to participate, and 51 patients for different reasons [Figure 1]. Finally, 54 patients fulfilling the inclusion criteria were recruited over a 2 -year period were included in the final analysis.

\section{Patient characteristics at randomization}

There were no significant differences between the two patient groups for the general characteristics at randomization as shown in Table 1. The median (range) age of patients included was 35 (17-82) years in selenium group and 41 (19-82) years in the control group, of which 44 patients $(86.3 \%)$ were male. The majority of patients included within $7 \pm 6$ days after ICU admission. The mean SOFA and APACHE II score on the day of admission were similar in both groups. The majority of patients included in the study were trauma patients $(33,61 \%)$ with equal randomization to both groups. The most common comorbidity in this study was hypertension $(11,20.3 \%)$ followed by diabetes mellitus $(4,7.4 \%)$. The site of infection and the type of organism involved did not significantly differ between the two groups at baseline.

\section{Clinical outcomes}

There was no significant difference between the two groups in 28-day mortality: $9(31 \%)$ in the selenium group versus $10(40 \%)$ in the control group $(P=0.69)$. There was a trend toward reduced in 60-day mortality in the selenium group compared with the control group, with mortality rate of $10(38.5 \%)$ in the selenium group versus $16(64 \%)$ in the control group $(P=0.07)$ [Figure 2 and Table 2]. The mean time to vasopressor therapy withdrawal was 3 and 5 days $(95 \%$ confidence interval; $1-5$ and 3-7 in the selenium and control 


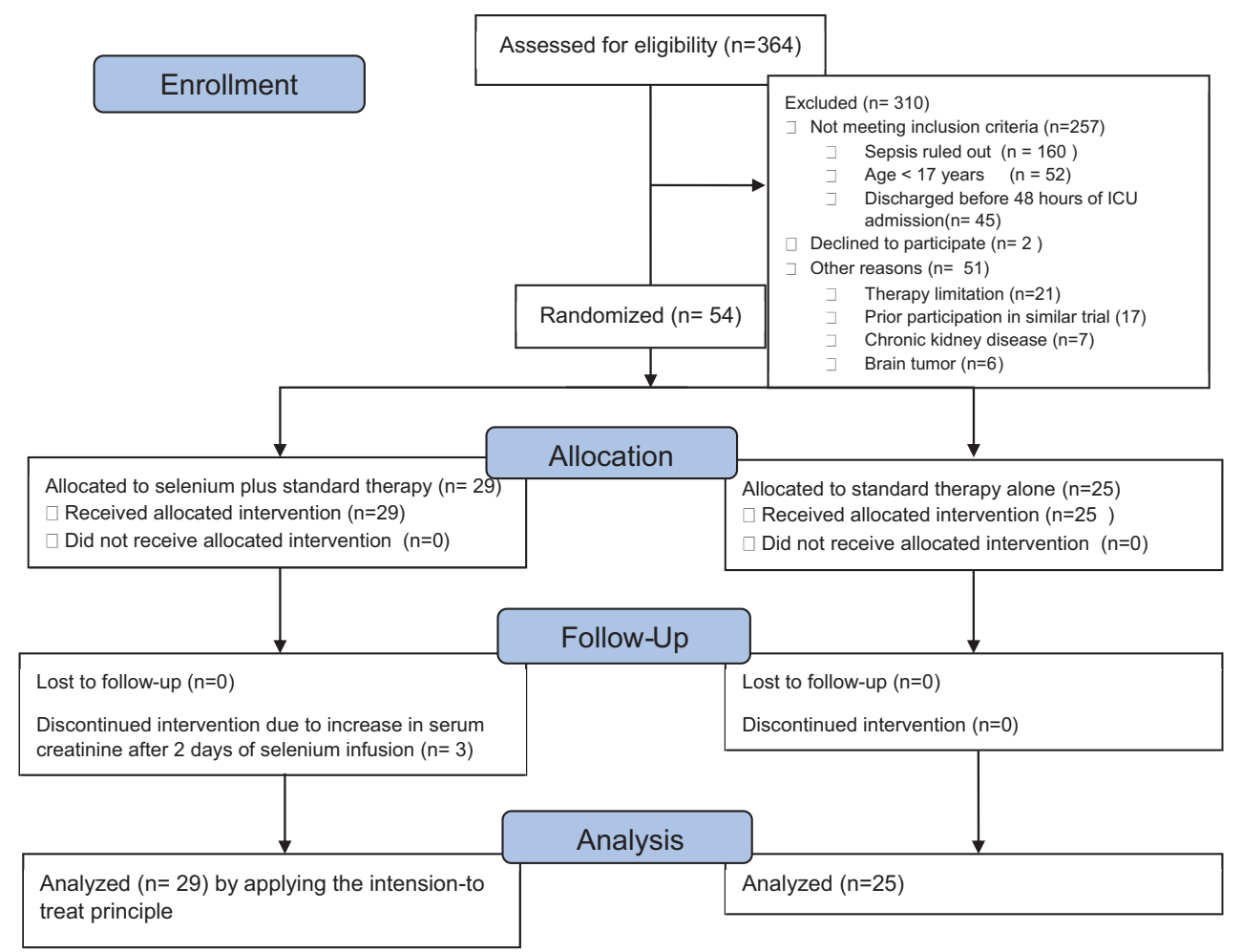

Figure 1: Study design and patient selection

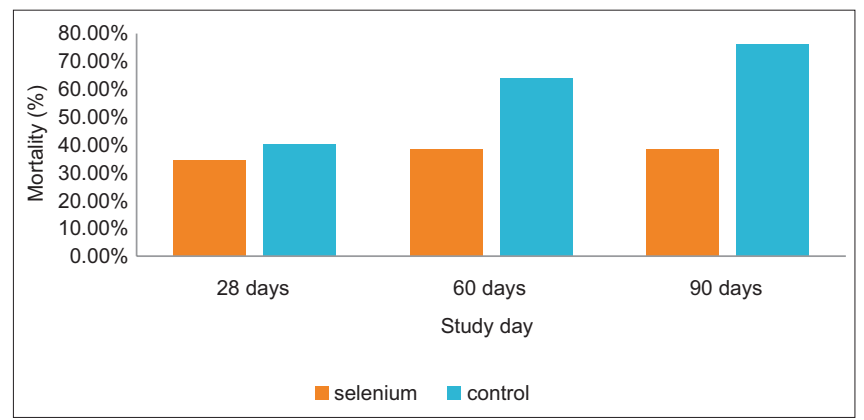

Figure 2: Bar chart shows the mortality rate in study patients at different time in point in study patients

groups, respectively, $P=0.09$ ). There was no statistically significant difference between the two groups with regard to renal failure.

\section{Changes in the levels of biomarkers}

There was no significant difference between the mean plasma levels of either HMGB-1 protein or SOD at any point in time over the course of 14 days between the two groups as shown in Table 3.

\section{Discussion}

The result of this RCT indicated that high dose of selenium supplementation has no effect on 28- and 60-day mortality in patients with severe sepsis and septic shock. The most important feature in this study was the inclusion of younger patients compared to previous studies. ${ }^{[23,28,32,33]}$ Our hospital is a level 1 trauma center. Most of these patients were admitted to the ICU after car/motorcycle injury, of which traumatic brain accidents was the most common. This group of patients stayed in the hospital for longer time and died because of recurrent hospital-acquired infections such as pneumonia and sepsis despite adequate resuscitation and appropriate antibiotic therapy. According to new studies, ${ }^{[10-12]}$ EGDT versus standard therapy has not changed 90-day mortality. That tells us other than fluid and antibiotics, other treatment alternatives may have survival benefits. Against this background this RCT was performed that involved administration of a bolus dose of $2 \mathrm{mg}$ over $1 \mathrm{~h}$ followed by $1.5 \mathrm{mg}$ continuous infusion over $24 \mathrm{~h}$ for 14 days with a total dose of $23 \mathrm{mg}$ in 14 days. The finding of this study indicated that there was an increase in the levels of glutathione peroxidase- 3 as reported elsewhere ${ }^{[39]}$ without the expected reduction of mortality. This dose was selected based on a previous study, ${ }^{[33]}$ in which high-dose sodium-selenite supplementation was found to be beneficial beneficial in sepsis and septic shock.

It was reported that selenium administration had no beneficial effects in case of low dose therapy in case of low dose therapy, absence of loading dose, and short-term administration. Based on this information, we used a high loading dose IV sodium selenite followed by continuous infusion for 14 days. In this study we found that does not improve the 28-day mortality as in the largest trial ever done $(n=1089)$ on selenium monotherapy and procalcitonin-guided antibiotic therapy $(n=1089)$ in patients with severe sepsis and septic shock. After giving 


\begin{tabular}{|c|c|c|c|}
\hline Characteristics & Selenium $(n=29)$ & Control $(n=25)$ & $P$ \\
\hline Age (year), media (IQR) & $35(17-82)$ & $41(19-82)$ & $0.18^{*}$ \\
\hline Male, $n(\%)$ & $22(84.6)$ & $22(88)$ & 0.53 \\
\hline $\begin{array}{l}\text { The time between the ICU admission and } \\
\text { enrollment to study (day) }(\operatorname{mean} \pm \mathrm{SD})\end{array}$ & $7 \pm 7$ & $7 \pm 6$ & 0.92 \\
\hline SOFA on admission $(\operatorname{mean} \pm \mathrm{SD})$ & $8 \pm 2.7$ & $8.3 \pm 2.98$ & 0.69 \\
\hline APACHE II score admission (mean \pm SD) & $17 \pm 4.3$ & $16.4 \pm 4.0$ & 0.71 \\
\hline \multicolumn{4}{|l|}{ Admission diagnosis, $n(\%)$} \\
\hline Trauma & $18(62)$ & $15(60)$ & 0.56 \\
\hline Abdominal surgery & $3(10.3)$ & $2(8)$ & \\
\hline Other surgery & $3(10.3)$ & $3(12)$ & \\
\hline Unfiled & $2(6.8)$ & $2(8)$ & \\
\hline Cerebrovascular accidents & 0 & $1(4)$ & \\
\hline Hemorrhagic shock & 0 & $1(4)$ & \\
\hline Pancreatitis & 0 & $1(4)$ & \\
\hline \multicolumn{4}{|l|}{ Comorbidities, $n(\%)$} \\
\hline Chronic obstructive pulmonary diseases & 0 & $1(4)$ & 0.490 \\
\hline Atrial fibrillation & 0 & $1(4)$ & 0.490 \\
\hline Heart failure & 0 & $1(4)$ & 0.490 \\
\hline Hypertension & $5(17.2)$ & $6(24)$ & 0.470 \\
\hline Ischemic heart diseases & $2(6.8)$ & $1(4)$ & 0.575 \\
\hline Diabetes mellitus & $2(6.8)$ & $2(8)$ & 0.967 \\
\hline \multicolumn{4}{|l|}{ Types of infection, $n(\%)$} \\
\hline Pneumonia & $15(51.7)$ & $19(76)$ & 0.373 \\
\hline Peritonitis & $7(24.1)$ & $3(12)$ & \\
\hline Skin and soft tissue infections & $3(10.3)$ & $2(8)$ & \\
\hline Central nervous system infections & 0 & $1(4)$ & \\
\hline Central line related infections & $1(3.5)$ & 0 & \\
\hline \multicolumn{4}{|l|}{ Severity of sepsis, $n(\%)$} \\
\hline Sepsis & $6(20.7)$ & $6(24)$ & 0.990 \\
\hline Severe sepsis & $7(24.1)$ & $7(28)$ & \\
\hline Septic shock & $13(44.8)$ & $12(48)$ & \\
\hline \multicolumn{4}{|l|}{ Pathogens, $n(\%)$} \\
\hline Gram-positive & $4(13.8)$ & $1(4)$ & 0.299 \\
\hline Gram-negative & $6(20.7)$ & $9(36)$ & \\
\hline No growth & $16(55.2)$ & $15(60)$ & \\
\hline
\end{tabular}

*Mann-Whitney U-test. IQR: Interquartile range; SD: Standard deviation; ICU: Intensive Care Unit; SOFA: Sequential Organ Failure Assessment; APACHE II: Acute Physiologic and Chronic Health Evaluation II

\section{Table 2: Study outcomes}

\begin{tabular}{|c|c|c|c|c|}
\hline Variable & Selenium group $(n=29)$ & Control group $(n=25)$ & OR (95\% Cl) & $P$ \\
\hline Duration of vasopressor therapy, mean ( $95 \%$ CI for mean) & $3(1-5)$ & $5(3-7)$ & & 0.09 \\
\hline Incidence of acute renal failure, $n(\%)$ & $5(17)$ & $7(28)$ & $0.82(2-9)$ & 0.80 \\
\hline 28 days mortality, $n(\%)$ & $9(31)$ & $10(40)$ & $0.8(0.255-2.48)$ & 0.69 \\
\hline 60 days mortality, $n(\%)$ & $10(34.5)$ & $16(64)$ & $0.35(0.113-1.10)$ & 0.07 \\
\hline
\end{tabular}

OR: Odds ratio; CI: Confidence interval

an IV loading dose of $1000 \mu \mathrm{g}$ sodium selenite followed by continuous infusion of $1000 \mu \mathrm{g}$ for no longer than 21 days, Bloos et al. ${ }^{[40]}$ found that selenium administration had no beneficial effect on 28-day mortality as well as on preventing secondary infection. On top of this, Bloos et al. also did not find any risk of increased renal failure. Our study was also unable to find any significant deleterious adverse renal outcome of selenium in critically ill patients following sepsis. Although not investigated elsewhere yet, we found that there was no beneficial effect of selenium on biomarkers such as HMGB-1 protein and SOD. In general, the current understanding of why high-dose selenium administration lacks beneficial effects in patients with severe sepsis and septic shock remains vague. Indeed, we cannot draw valid conclusion based on this study since we included small sample size. Nevertheless, it is not possible to extrapolate lack of beneficial effects in critically 
Table 3: Levels of high mobility group box-1 and superoxide dismutase at different times in study patients

\begin{tabular}{lccc}
\hline Levels of biomarker** & \multicolumn{2}{c}{ Mean \pm SD } & $P$ \\
\cline { 2 - 3 } & $\begin{array}{c}\text { Selenium } \\
\text { group }(\boldsymbol{n = 2 9})\end{array}$ & $\begin{array}{c}\text { Control } \\
\text { group }(\boldsymbol{n}=\mathbf{2 5})\end{array}$ \\
\hline HMGB-1 on day 0 & $3.1 \pm 2.0$ & $3.4 \pm 2$ & 0.58 \\
HMGB-1 on day 3 & $1.4 \pm 0.5$ & $2.6 \pm 2$ & 0.08 \\
HMGB-1 on day 7 & $2 \pm 2$ & $3.9 \pm 4$ & 0.67 \\
HMGB-1 on day 10 & $1.7 \pm 1$ & $2.5 \pm 1$ & 0.097 \\
HMGB-1 on day 14 & $3.7 \pm 6$ & $3.2 \pm 3$ & 0.70 \\
SOD day 0 & $0.6 \pm 0.3$ & $0.4 \pm 0.4$ & 0.35 \\
SOD day 3 & $0.4 \pm 0.4$ & $0.5 \pm 0.2$ & 0.47 \\
SOD day 7 & $0.5 \pm 0.3$ & $0.7 \pm 0.4$ & 0.59 \\
SOD day 10 & $0.5 \pm 0.4$ & $0.7 \pm 0.4$ & 0.68 \\
SOD day 14 & $0.6 \pm 0.3$ & $0.5 \pm 0.3$ & 0.51 \\
\hline
\end{tabular}

**Repeated measures of variance (ANOVA) was used. Levels of HMGB-I measured in $\mathrm{pg} / \mathrm{mL}$, activities of SOD measured in $(\mathrm{U} / \mathrm{mL})$. SD: Standard deviation; HMGB-1: High mobility group box-1; SOD: Superoxide dismutase

ill patients to other population as IV selenium after cardiac surgery showed beneficial effects.

One of the strengths of our trial was the fact that we administered selenium within the first $6 \mathrm{~h}$ of diagnosis of sepsis to observe its effect early in sepsis and a larger trial is indicated to exclude effects of the small sample size in this study. Moreover, we analyzed the effect of selenium on HMGB-1 protein, the effect never studied before to our knowledge. However, our study was not without limitations. The sample size as noted above was too small to detect the expected differences between the two groups in terms of outcomes. Second, the study was single centered which did not include diverse population and lacked external validity. Furthermore, the current study was single-blinded study its attendant bias.

\section{ConcLusion}

With early administration of high-dose IV sodium selenite this study demonstrated that neither mortality (28 and 60 days) nor the mean levels of HMGB-1 and SOD is reduced as compared to controls. In this underpowered study, high dose Selenium supplementation in septic shock does not improve clinical or measurable inflammatory response.

\section{Financial support and sponsorship}

Tehran University of Medical Sciences, International campus(TUMS-IC)

\section{Conflicts of interest}

There are no conflicts of interest.

\section{References}

1. Angus DC, Linde-Zwirble WT, Lidicker J, Clermont G, Carcillo J, Pinsky MR. Epidemiology of severe sepsis in the United States: Analysis of incidence, outcome, and associated costs of care. Crit Care Med 2001;29:1303-10.

2. Daniels R. Surviving the first hours in sepsis: Getting the basics right (an intensivist's perspective). J Antimicrob Chemother 2011;66 Suppl 2:ii11-23.

3. Kaczorowski DJ, Nakao A, Vallabhaneni R, Mollen KP, Sugimoto R, Kohmoto J, et al. Mechanisms of toll-like receptor 4 (TLR4)-mediated inflammation after cold ischemia/reperfusion in the heart. Transplantation 2009;87:1455-63.

4. Angus DC, van der Poll T. Severe sepsis and septic shock. N Engl J Med 2013;369:840-51.

5. Bianchi ME. DAMPs, PAMPs and alarmins: All we need to know about danger. J Leukoc Biol 2007;81:1-5.

6. Sundén-Cullberg J, Norrby-Teglund A, Rouhiainen A, Rauvala H, Herman G, Tracey KJ, et al. Persistent elevation of high mobility group box-1 protein (HMGB1) in patients with severe sepsis and septic shock*. Crit Care Med 2005;33:564-73.

7. Gibot S, Massin F, Cravoisy A, Barraud D, Nace L, Levy B, et al. High-mobility group box 1 protein plasma concentrations during septic shock. Intensive Care Med 2007;33:1347-53.

8. Dellinger RP, Levy MM, Rhodes A, Annane D, Gerlach H, Opal SM, et al. Surviving sepsis campaign: International guidelines for management of severe sepsis and septic shock, 2012. Intensive Care Med 2013;39:165-228.

9. Rivers E, Nguyen B, Havstad S, Ressler J, Muzzin A, Knoblich B, et al. Early goal-directed therapy in the treatment of severe sepsis and septic shock. N Engl J Med 2001;345:1368-77.

10. ProCESS Investigators, Yealy DM, Kellum JA, Huang DT, Barnato AE, Weissfeld LA, et al. A randomized trial of protocol-based care for early septic shock. N Engl J Med 2014;370:1683-93.

11. ARISE Investigators; ANZICS Clinical Trials Group, Peake SL, Delaney A, Bailey M, Bellomo R, Cameron PA, et al. Goal-directed resuscitation for patients with early septic shock. N Engl J Med 2014;371:1496-506.

12. Mouncey PR, Osborn TM, Power GS, Harrison DA, Sadique MZ, Grieve RD, et al. Trial of early, goal-directed resuscitation for septic shock. N Engl J Med 2015;372:1301-11.

13. Hotchkiss RS, Opal S. Immunotherapy for sepsis - A new approach against an ancient foe. N Engl J Med 2010;363:87-9.

14. Wang Z, Forceville X, Van Antwerpen P, Piagnerelli M, Ahishakiye D, Macours $\mathrm{P}$, et al. A large-bolus injection, but not continuous infusion of sodium selenite improves outcome in peritonitis. Shock 2009;32:140-6.

15. Driscoll DM, Copeland PR. Mechanism and regulation of selenoprotein synthesis. Annu Rev Nutr 2003;23:17-40.

16. Alonso de Vega JM, Díaz J, Serrano E, Carbonell LF. Oxidative stress in critically ill patients with systemic inflammatory response syndrome. Crit Care Med 2002;30:1782-6.

17. Motoyama T, Okamoto K, Kukita I, Hamaguchi M, Kinoshita Y, Ogawa H. Possible role of increased oxidant stress in multiple organ failure after systemic inflammatory response syndrome. Crit Care Med 2003;31:1048-52.

18. Sakr Y, Reinhart K, Bloos F, Marx G, Russwurm S, Bauer M, et al. Time course and relationship between plasma selenium concentrations, systemic inflammatory response, sepsis, and multiorgan failure. $\mathrm{Br}$ Anaesth 2007;98:775-84.

19. Brealey D, Brand M, Hargreaves I, Heales S, Land J, Smolenski R, et al. Association between mitochondrial dysfunction and severity and outcome of septic shock. Lancet 2002;360:219-23.

20. Avenell A, Noble DW, Barr J, Engelhardt T. Selenium supplementation for critically ill adults. Cochrane Libr 2004. Available from: https://www. ncbi.nlm.nih.gov/pubmed/15495061. [Last accessed on 2016 Dec 23].

21. Heyland DK, Dhaliwal R, Suchner U, Berger MM. Antioxidant nutrients: A systematic review of trace elements and vitamins in the critically ill patient. Intensive Care Med 2005;31:327-37.

22. Manzanares W, Dhaliwal R, Jiang X, Murch L, Heyland DK Antioxidant micronutrients in the critically ill: A systematic review and meta-analysis. Crit Care 2012;16:R66.

23. Manzanares W, Biestro A, Torre MH, Galusso F, Facchin G, Hardy G. High-dose selenium reduces ventilator-associated pneumonia and illness severity in critically ill patients with systemic inflammation. Intensive Care Med 2011;37:1120-7.

24. Berger MM, Reymond MJ, Shenkin A, Rey F, Wardle C, Cayeux C, et al. Influence of selenium supplements on the post-traumatic 
alterations of the thyroid axis: A placebo-controlled trial. Intensive Care Med 2001;27:91-100.

25. Berger MM, Spertini F, Shenkin A, Wardle C, Wiesner L, Schindler C, et al. Trace element supplementation modulates pulmonary infection rates after major burns: A double-blind, placebo-controlled trial. Am J Clin Nutr 1998;68:365-71.

26. Berger MM, Soguel L, Shenkin A, Revelly JP, Pinget C, Baines M, et al. Influence of early antioxidant supplements on clinical evolution and organ function in critically ill cardiac surgery, major trauma, and subarachnoid hemorrhage patients. Crit Care 2008;12:R101.

27. Andrews PJ, Avenell A, Noble DW, Campbell MK, Croal BL, Simpson WG, et al. Randomised trial of glutamine, selenium, or both, to supplement parenteral nutrition for critically ill patients. BMJ 2011;342:d1542.

28. Forceville X, Laviolle B, Annane D, Vitoux D, Bleichner G, Korach JM, et al. Effects of high doses of selenium, as sodium selenite, in septic shock: A placebo-controlled, randomized, double-blind, phase II study. Crit Care 2007;11:R73.

29. Lindner D, Lindner J, Baumann G, Dawczynski H, Bauch K. Investigation of antioxidant therapy with sodium selenite in acute pancreatitis. A prospective randomized blind trial. Med Klin (Munich) 2004;99:708-12.

30. Kuklinski B, Zimmermann T, Schweder R. Decreasing mortality in acute pancreatitis with sodium selenite. Clinical results of 4 years antioxidant therapy. Med Klin (Munich) 1995;90 Suppl 1:36-41.

31. Angstwurm MW, Schottdorf J, Schopohl J, Gaertner R. Selenium replacement in patients with severe systemic inflammatory response syndrome improves clinical outcome. Crit Care Med 1999;27:1807-13.

32. Mishra V, Baines M, Perry SE, McLaughlin PJ, Carson J, Wenstone R, et al. Effect of selenium supplementation on biochemical markers and outcome in critically ill patients. Clin Nutr 2007;26:41-50.
33. Angstwurm MW, Engelmann L, Zimmermann T, Lehmann C, Spes CH, Abel P, et al. Selenium in Intensive Care (SIC): Results of a prospective randomized, placebo-controlled, multiple-center study in patients with severe systemic inflammatory response syndrome, sepsis, and septic shock*. Crit Care Med 2007;35:118-26.

34. Kong Z, Wang F, Ji S, Deng X, Xia Z. Selenium supplementation for sepsis: A meta-analysis of randomized controlled trials. Am J Emerg Med 2013;31:1170-5.

35. Visser J, Labadarios D, Blaauw R. Micronutrient supplementation for critically ill adults: A systematic review and meta-analysis. Nutrition 2011;27:745-58.

36. Miller N, Miller M, Hill LT. The impact of antioxidant supplementation on clinical outcomes in the critically ill: A meta-analysis. South Afr J Crit Care 2013;29:18-26.

37. Huang TS, Shyu YC, Chen HY, Lin LM, Lo CY, Yuan SS, et al. Effect of parenteral selenium supplementation in critically ill patients: A systematic review and meta-analysis. PLoS One 2013;8:e54431.

38. Bone RC, Balk RA, Cerra FB, Dellinger RP, Fein AM, Knaus WA, et al. Definitions for sepsis and organ failure and guidelines for the use of innovative therapies in sepsis. The ACCP/SCCM Consensus Conference Committee. American College of Chest Physicians/Society of Critical Care Medicine. Chest 1992;101:1644-55.

39. Chelkeba L, Ahmadi A, Abdollahi M, Najafi A, Ghadimi MH, Mosaed R, et al. The effect of parenteral selenium on outcomes of mechanically ventilated patients following sepsis: A prospective randomized clinical trial. Ann Intensive Care 2015;5:29.

40. Bloos F, Trips E, Nierhaus A, Briegel J, Heyland DK, Jaschinski $\mathrm{U}$, et al. Effect of sodium selenite administration and procalcitonin-guided therapy on mortality in patients with severe sepsis or septic shock: A randomized clinical trial. JAMA Intern Med 2016;176:1266-76. 